\title{
Investigation on public knowledge, attitude and practices related to pet management and zoonotic canine diseases in Addis Ababa, Ethiopia
}

\author{
Bitsu Kiflu ${ }^{1}$, Mukarim Abdurahaman ${ }^{1}$, Haile Alemayehu ${ }^{2}$ and Tadesse Eguale ${ }^{2^{*}}$ \\ ${ }^{1}$ Jimma University College of Agriculture and Veterinary Medicine, P. O. Box 307, Jimma, Ethio- \\ pia
}

${ }^{2}$ Aklilu Lemma Institute of Pathobiology, Addis Ababa University, P. O. Box 1176, Addis Ababa, Ethiopia

*Corresponding author: Aklilu Lemma Institute of Pathobiology, Addis Ababa University, P. O. Box 1176, Addis Ababa,Ethiopia,Email: tadesse.eguale@aau.edu.et

http://dx.doi.org/10.4314/evj.v20i1.5

\begin{abstract}
Many infectious diseases are transmitted from animals to human and the other way. Despite this there is limited information about public knowledge on pet husbandry and diseases control practices in Addis Ababa. The objectives of this study are to assess the knowledge, attitude and practices towards pet husbandry, contact-related attitude and zoonotic diseases among dog-owning households in Addis Ababa. A cross-sectional questionnaire based study was conducted to assess the public's perception. A total of 252 dog-owning households from four sub-cities of Addis Ababa were interviewed using structured questionnaire. Of the total 252 respondents, majority of them $(70.2 \%)$ did not take their dog to veterinary service on regular basis (at least once a year). Over half of the respondents (59.1\%) fed raw meat to their dogs and $79.3 \%$ of the owners obtained the meat from local unlicensed markets. The majority of the respondents (87\%) in the current study believed the risk of acquiring zoonotic diseases from dogs. However, most of them (95.4\%) knew only rabies and only $4.6 \%$ of them knew parasitic diseases in addition to rabies. Only $61.9 \%$ of the respondents reported having ever received information about pet-associated diseases or precautions to reduce the risk of these diseases. Out of those who received information, $48 \%$ of them obtained from their friends and/or relatives. Only $9 \%$ and $9.6 \%$ of them received information from veterinarians and health workers, respectively. The result suggests a need for awareness creation on proper pet management and zoonotic diseases prevention practices for pet-owning households, with concerted efforts by veterinary, human and public health professionals.
\end{abstract}

Keywords: Attitude, Canine zoonosis, Knowledge, Practices 


\section{Introduction}

Dog (Canis familiaris) is known to be kept as first pet and first domesticated species since prehistoric times (Kuma and Smith, 2000; Smith and Whitfield, 2012). Throughout those years, the role of dogs in human life has changed from one of guardian and hunting companion, to farm hand and most recently, pet and family member (Leonard, 2014). There are many potential benefits to having dogs. Those benefits include companionship, physical activity, protection, improved mental health and stress relief, animal-assisted therapies, and increased independence for those with disabilities (Hodgson and Darling, 2011; Beetz et al., 2012a; Beetz et al., 2012b). However, concerns about the transmission of zoonotic infections between dogs and humans have been raised (Leonard, 2014). Pet-associated zoonoses represent a relatively neglected area compared to food borne zoonoses. However, the close contact between household pets and people offers favorable conditions for transmission of diseases by direct contact (e.g. petting, licking or physical injuries) or indirectly through contamination of food and domestic environments (Song et al., 2013).

Many of the disease risks that occur with pet contact can be eliminated or reduced through simple measures, such as hand hygiene, proper animal husbandry and altered animal-contact behaviors. Thus, awareness on good pet husbandry, sanitation practices and zoonotic disease risk of pets is a prerequisite for effective disease prevention (Stull, 2012). To-date, few studies have evaluated the general public's knowledge, attitude and practices (KAP) towards pet husbandry and pet-associated zoonoses in Addis Ababa. Most KAP studies done so far were concentrated on rabies (Abraham Ali et al., 2013; Eshetu Yimer et al., 2012; Tadesse Guadu et al., 2014).

Understanding communities' perceptions towards dog husbandry, contact and zoonotic diseases knowledge is an important step towards the development and implementation of appropriate disease prevention and control strategies. Therefore, the objectives of this study were to assess the communities' knowledge, attitude and perception regarding pet management, zoonotic canine diseases and their public health implication. 


\section{Materials and Methods}

\section{Description of the study area}

The study was conducted in Addis Ababa, which is the capital city and administration center for the Federal Democratic Republic of Ethiopia. Addis Ababa lies $9^{\circ} 1^{\prime} 48^{\prime \prime}$ North and $38^{\circ} 44^{\prime} 24^{\prime \prime}$ East (AACG, 2013). It lies in the central highlands of Ethiopia at an altitude of 2500 meters above sea level. It has an average rainfall of $1800 \mathrm{~mm}$ per annum. The annual average maximum and minimum temperature is $26^{\circ} \mathrm{C}$ and $11^{\circ} \mathrm{C}$, respectively; with an overall average of $18.7^{\circ} \mathrm{C}$ (NMSA, 2012). The city is divided in to 10 sub-cities (Kifle Ketemas) delineated on the basis of geographical set up, population density, asset and service providers' distribution and convenience for administration. The sub-cities are also divided in to woredas, which are the smallest administrative unit in the city. There are 116 woredas in the city administration (AACG, 2013).

\section{Study population and method}

A cross sectional study was conducted by using a closed-ended semi structured questionnaire which was focused on assessing the public knowledge, attitude and practices towards pet husbandry, contact-related attitude, sanitation practice and their knowledge on canine zoonotic diseases. The questionnaire was administered to 252 dog owners from 4 randomly selected kifle ketemas (Gulele, Yeka, Arada and Kirkos). Questions were answered by a single adult from a given household. The questionnaire includes questions like: the type of food and water given to the dogs, the place where the food brought, the frequency and the type of contact the owners had with their dogs, sanitation practices, their knowledge about canine zoonoses and their source of information about these diseases.

\section{Data analysis}

The collected data were entered into Excel sheets, which were imported and analyzed using statistical package for social sciences (SPSS version 20.0). Descriptive statistics (frequency and percentage) and graphs were computed for all variables. 


\section{Results}

Proportion of dog owners involved in the study among 4 sub-cities and purpose of dog ownership are shown in Table 1. Of 252 dog owners, 91 (36.1\%) of them owned dogs for guard purpose, 101(40.1\%) for both guard and hobby, whereas only $60(23.8 \%)$ kept dogs for hobby.

Table 1: Sub-cities included in the study and purpose of dog ownership status of the respondents

\begin{tabular}{llc}
\hline Characteristics & Variables & Numbers (\%) \\
\hline & Gulele & $85(33.7)$ \\
& Arada & $55(21.8)$ \\
Sub-cities from which dog-owners & Kirkos & $58(23)$ \\
were interviewed & Yeka & $54(21.4)$ \\
Purpose of dog ownership & Guard & $91(36.1)$ \\
& Hobby & $60(23.8)$ \\
& Guard and Hobby & $101(40.1)$ \\
\hline
\end{tabular}

The study showed that majority of the owners 177 (70.2\%) did not take their dog to veterinary services on a regular basis (at least once a year) and 216 (85.7\%) of them did not give their dogs any medicine (Table 2). Most of the owners 232 (92.1\%) provided meat to their dogs, of which 137 (59.1\%) of them fed raw meat, 80 (34.5\%) of dog owners fed their dog with cooked meat, while 15 (6.4\%) of them fed both raw and cooked meat. In addition, majority of the dogs $230(91.3 \%)$ were fed table scraps/human foods and only $9(3.6 \%)$ of the dogs were fed commercial pet foods.

One hundred eighty-four (79.3\%) of the owners obtained the meat from local unlicensed markets. These unlicensed dealers collect different left over of meat such as legs, heads, offal's of sheep, goats and cattle from hotels and butchers and sell them to dog owners at open air markets. Only $46(19.8 \%)$ of the owners obtained the meat from licensed butchers which sell meats for human consumption. A very small number of the owners $2(0.9 \%)$ obtained the meat from supermarkets. All the respondents reported that they give a clean municipal drinking water for their dogs. Besides the clean water they provided, 52 $(20.6 \%)$ and $36(14.3 \%)$ of the dog owners responded that their dogs sometimes drink rain water and water from toilet bowls, respectively (Table 2). Sixty- 
eight $(27 \%)$ of the respondents reported that they allow their dogs to sleep in their living room and about half 121 (48\%) of dog owners allowed their dog to have contact, sit and/or sleep on their furniture.

Table 2: Knowledge attitude and practice of the respondents on pet husbandry

\begin{tabular}{|c|c|c|c|}
\hline \multicolumn{2}{|l|}{ Variables } & Yes, N (\%) & No, $N(\%)$ \\
\hline \multicolumn{2}{|c|}{ See a Veterinarian on a regular basis (at least once a year)? } & $75(29.8)$ & $177(70.2)$ \\
\hline \multicolumn{2}{|c|}{ Did you give the dog any medicine for diseases? } & $36(14.3)$ & $216(85.7)$ \\
\hline \multicolumn{2}{|l|}{ Sit and/or sleep on furniture } & $121(48)$ & 131(52) \\
\hline \multirow{4}{*}{$\begin{array}{l}\text { Where does your dog spend } \\
\text { majority of its time? }\end{array}$} & All the time in the house & $154(61.1)$ & \\
\hline & Mostly in the house & $68(27)$ & \\
\hline & Half inside & $17(6.7)$ & \\
\hline & Mostly outside & $13(5.2)$ & \\
\hline \multirow[t]{5}{*}{ Where does your dog sleep? } & In the living room & $68(27)$ & \\
\hline & Dogs house & $135(53.6)$ & \\
\hline & $\begin{array}{l}\text { In the living room and dogs } \\
\text { house }\end{array}$ & $19(7.5)$ & \\
\hline & Outside the house & $18(7.1)$ & \\
\hline & Outside the compound & $12(4.8)$ & \\
\hline \multirow[t]{3}{*}{ What do you feed your dog? } & Meat & $232(92.1)$ & $20(7.9)$ \\
\hline & Table scrap/human food & $230(91.3)$ & $22(8.7)$ \\
\hline & Commercial food & $9(3.6)$ & $243(96.4)$ \\
\hline \multirow{3}{*}{$\begin{array}{l}\text { What type of meat do you } \\
\text { feed to your dog? }\end{array}$} & Raw & $137(59.1)$ & \\
\hline & cooked & $80(34.5)$ & \\
\hline & Raw and cooked & $15(6.4)$ & \\
\hline \multirow[t]{4}{*}{$\begin{array}{l}\text { Where do you obtain the } \\
\text { meat? }\end{array}$} & Local market & $184(79.3)$ & \\
\hline & Licensed butcher & $46(19.8)$ & \\
\hline & Supermarket & $2(0.9)$ & \\
\hline & Rain water & $52(20.6)$ & $200(79.4)$ \\
\hline $\begin{array}{l}\text { Does your dog drink unclean } \\
\text { water? }\end{array}$ & Water from the toilet bowl & $36(14.3)$ & $216(85.7)$ \\
\hline
\end{tabular}

Ethiop. Vet. J., 2016, 20 (1), 67-78 
Two hundred twelve (84.1\%) of the respondents had experience of touching their dogs on regular basis, while $130(51.6 \%)$ of the respondents or their family had experience of direct or indirect mouth contact with dogs. Ninety six (38.1\%) of them reported that at least one member of their family had a contact with feces of the dogs. Close contact between dogs and children was often reported, as 68 (27\%) of the respondents stated that their dog slept in a living room including child's bed room (Table 2). One hundred sixty seven $(78.8 \%)$ of the respondents washed their hands after having contact with their dogs of which $34.1 \%, 35.3 \%$ and $30.5 \%$ of them wash always, usually and sometimes, respectively. $45(21.2 \%)$ of the respondents never washed their hands after having contact with their dog (Table 3).

Table 3: Sanitation and pet contact related attitude of the respondents

\begin{tabular}{|c|c|c|c|}
\hline Variables & & Yes, N (\%) & No, $N(\%)$ \\
\hline Touching the dog & & $212(84.1)$ & $40(15.9)$ \\
\hline Having mouth contact with any part of the dog & & $130(51.6)$ & $122(48.4)$ \\
\hline $\begin{array}{l}\text { Touching or having any contact with the dogs } \\
\text { faces }\end{array}$ & & $96(38.1)$ & $156(61.9)$ \\
\hline $\begin{array}{l}\text { Do you (any member of family) wash their } \\
\text { hands after touching the dog? }\end{array}$ & & $167(78.8)$ & $45(21.2)$ \\
\hline \multirow[t]{3}{*}{ How often? } & Always & $57(34.1)$ & \\
\hline & Usually & $59(35.3)$ & \\
\hline & Sometimes & $51(30.5)$ & \\
\hline $\begin{array}{l}\text { Do any of the children (member of your family) } \\
\text { play in the same area as where the dog(s) go to } \\
\text { the bathroom? }\end{array}$ & & $115(45.6)$ & $137(54.4)$ \\
\hline
\end{tabular}

Of 252 respondents, 219 (87\%) of them knew a disease that can be transmitted from dogs to human. Of which, 209 (95.4\%) of them knew only rabies and $4.6 \%$ of them rabies and parasitic diseases as well. None of the respondents had knowledge about any other disease that can be transmitted from pets to human except rabies and parasitic diseases. Even those respondents who reported that they knew parasitic diseases that can be acquired from dogs, none of them were able to name a single zoonotic parasitic disease. 
One hundred fifty six $(61.9 \%)$ of the respondents received information regarding zoonotic diseases that can be acquired from dogs, of which 75 (48\%) of them obtained this information from their friends and relatives whereas, only $14(9 \%)$ and $15(9.6 \%)$ of them received information from veterinarians and human health workers, respectively. Only 13 (8.3\%) received the information from media (Table 4).

Table 4: Zoonotic disease knowledge and educational source of respondent

\begin{tabular}{llcc}
\hline Variables & & Yes N (\%) & No N (\%) \\
\hline $\begin{array}{l}\text { Do you know a disease that is transmitted } \\
\text { from dog to human }\end{array}$ & $219(87)$ & $33(13)$ \\
If yes what? List them & $\begin{array}{l}\text { Rabies } \\
\text { Rabies and }\end{array}$ & $109(95.4)$ & \\
& $\begin{array}{l}\text { Parasites } \\
\text { Have you ever received information from }\end{array}$ & & \\
$\begin{array}{l}\text { any source about diseases that you can get } \\
\text { from dogs or precautions to take with dogs }\end{array}$ & & \\
to reduce the risk of disease? & $156(61.9)$ & $96(38.1)$ \\
If yes, from where? & & \\
Friends and Relatives/Exposure & & \\
Veterinarians & $75(48)$ & \\
Health workers & $14(9)$ \\
Medias & $15(9.6)$ & \\
Internet and Books & $13(8.3)$ \\
School/collage/university & $6(3.8)$ & \\
Friends/Relatives +Vets & $10(6.4)$ \\
Friends/Relatives +Health workers & $7(4.5)$ \\
Friends/Relatives +Medias & $9(5.7)$ \\
\hline
\end{tabular}

\section{Discussion}

This study revealed that majority (70.2\%) of the respondents doesn't take their dog to veterinary service (at least once per year) and $85.7 \%$ of them don't give any medicine for their dogs. This result indicates that most of dog owners in Addis Ababa give a little care for their dog's health presumably due to the fact that they don't believe that their dogs need medical treatment when they get 
sick. Most of them believed rabies as the sole disease of dog and anti-rabies vaccination can protect their dogs from any health problem.

The increasing popularity of raw food diets for companion animals is a major potential source of zoonotic pathogens (Finley et al., 2006). Several studies reported the contamination of these diets and their ingredients with pathogenic bacteria (Freeman and Michel, 2001; Weese et al., 2005; Strohmeyer et al., 2006; Finley et al., 2008). In this study most (92.1\%) of the owners fed their dogs with meat, of which $59 \%$ of them fed raw meat. This result is inconsistent with the study in Canada, by Stull et al. (2013), which reported only $28 \%$ of the dog owners fed raw eggs, raw meat, or raw animal product to their dogs. This is mainly due to difference in the economic status of the dog owners and in countries like Ethiopia, even if there are some dog owners who can afford commercial pet food, it is not readily available on market.

The fact that over $50 \%$ of the households had direct or indirect contact with their dogs implies high risk of contracting zoonotic diseases from dogs. These estimates are similar to a previous study in Netherlands in which dogs were permitted to lick their owners' face (50\%) and 18\%, reportedly slept in an adult's bed (Overgaauw et al., 2009). Hand hygiene plays a critical role in reducing the risk of zoonotic infections. In this study, the reported hand washing after having direct contact with the dog was high (78.8\%). In contrast to this finding, most of dog owners in developed countries wash their hands less frequently after having contact with their dogs. Overgaauw et al. (2009) reported that $50 \%$ of dog owners in Netherlands washed their hands after having contact with their dogs and only 15\% of dog owners in Cheshire, England Westgarth et al. (2008). The reason for this difference could be as most dog owners in developed countries give much attention to husbandry, sanitation and health of their dogs, they don't wash their hand all the time after having contact, because they believe that their pets are healthy. The level of hand hygiene documented in our study is likely adequate for those households which cares about the hygienic status of their dogs; however, for owners who are not concerned about hygienic status of their dog, hand washing should always be practiced (Stull et al., 2013).

Although $87 \%$ of the respondents in the current study knew the risk of acquiring zoonotic diseases from dogs, only $4.6 \%$ of them knew parasitic diseases besides rabies while majority of them knows only rabies. Their knowledge 
about rabies itself was not full and comprehensive, as some of the respondents believed that rabies can be transmitted by air and can be treated with traditional medicines. The respondents did not know any other disease that can be transmitted from dogs to human. In line with this finding, a study in Hawassa (Dejene G/selasie et al., 2013) showed that $85.7 \%$ of respondents have awareness about zoonotic canine diseases. However, their awareness was mainly restricted to rabies which accounted for $97 \%$ and only few of them had awareness about canine zoonotic parasites (3\%). In another study in Ambo, only 44.3\% of the owners had awareness about the role of dogs in transmitting diseases to human (Endrias Zewdu et al., 2010). This awareness was also restricted to rabies; none of them had awareness of other canine zoonotic diseases.

As awareness on risk of zoonotic diseases is a prerequisite for effective prevention, the limited zoonotic disease knowledge of the public is a serious concern. The low awareness on zoonotic diseases in the current study is not surprising as only $61.9 \%$ of respondents reported having ever received information about pet-associated diseases. About half (48\%) of the respondents obtained this information from their friends or relatives. Only $9 \%$ and $9.6 \%$ of them received information from veterinarians and health workers respectively. By contrast Bingham et al., (2010) in USA and Palmer et al. (2010) in Australia reported that veterinarians and internet were the two most frequent sources of information. Another study in New York (Gursimrat and Devinder, 2014) reported that $40 \%$ of participants reported the veterinarian as their primary source of information, while $20 \%$ and $5 \%$ of the participants reported internet and media as their source of information respectively.

\section{Conclusion}

In our study, however, the proportion of individuals who received information from veterinarians was very low. In order to minimize zoonotic diseases that can be acquired from dogs and other pet animals; veterinarians, public health workers, schools and Medias should play their role in creating awareness. There must be an integrated approach which enables the various stakeholders to create awareness on the risk of contracting zoonotic diseases from dogs and other pets and on the importance of proper husbandry and sanitation of pets. 


\section{Acknowledgements}

The authors would like to thank Veterinarians and animal health professionals working at Semen Mazegaja, Shola, Arada and Kera sub-city veterinary clinics, for their all kind help during the course of data collection.

\section{References}

AACG, 2013. Addis Ababa City Government: Bureau of Finance and Economic Development. Socio-Economic Profile of Addis Ababa for the Year 2012. Policy Study and Analysis Sub Process.

Ali, A., Yimer, E. and Sifer, D., 2013. A study on knowledge, attitude and practice of rabies among resident s in Addis Ababa, Ethiopia. Ethiop. Vet. J., 17(2), 19-35.

Beetz, A., Julius, H., Turner, D. and Kotrschal, K., 2012a. Effects of social support by a dog on stress modulation in male children with insecure attachment. Front Psychol., 3, 352 .

Beetz, A., Uvnas-Moberg, K., Julius, H. and Kotrschal, K., 2012b. Psychosocial and psychophysiological effects of human animal interactions: The possible role of oxytocin. Front Psychol., 3, 234.

Bingham, G.M., Budke, C.M. and Slater, M.R., 2010. Knowledge and perceptions of dog-associated zoonoses: Brazos County, Texas, USA. Prev. Vet. Med., 93, 211-221.

Chomel, B.B. and Sun, B., 2011. Zoonoses in the bed room. Emerg. Infect. Dis., 17, 167172 .

Finley, R., Reid-Smith, R., Ribble, C., Popa, M., Vandermeer, M. and Aramini, J., 2008. The occurrence and antimicrobial susceptibility of salmonellae isolated from commercially available canine raw food diets in three Canadian cities. Zoonoses Public Health, 55, 462-469.

Finley, R., Reid-Smith, R., Weese, J. and Angulo, F., 2006. Human health implications of Salmonella contaminated natural pet treats and raw pet food. Clin. Inft. Dis., 42, 686-691.

Freeman, L. and Michel, K., 2001. Evaluation of raw food diets for dogs. J. Am. Vet. Med. Assoc., 218, 705-709.

G/selasie, D., Geyola, M., Dagne, E., Asmare, K. and Mekuria and S., 2013. Gastrointestinal helminthes in dogs and community perception on parasite zoonosis at hawassa city, Ethiopia. Global Vet., 11 (4), 432-440 
Guadu, T., Shite, A., Chanie, M., Bogale, B. and Fentahun, T., 2014. Assessment of knowledge, attitude and practices about rabies and associated factors in Bahir Dar town. Global Vet., 13 (3), 348-354

Gursimrat, K. and Devinder, S., 2014. Level of awareness regarding some zoonotic diseases, among dog owners of ithaca New York. J. Family Med. Prim. Care., 3(4), 418-423.

Hodgson, K. and Darling, M., 2011. Pets in the family: Practical approaches. J. Am. Anim. Hosp. Assoc., 47, 299-305.

Kuma, G. and Smith, H., 2002. Pets, poop and parasites, Microbiology today., 27, 84-86

Leonard, E.K., 2014. What could your dog be carrying zoonotic enteric bacteria in pet dogs in ontario: prevalence, risk factors, and antimicrobial resistance. A Phd Thesis presented to The University of Guelph, Ontario, Canada. Pp. 4

NMSA, 2012. National Meteorological Service Agency: Rainfall and temperature data, Addis Ababa, Ethiopia.

Overgaauw, P., Van-Zutphen, L., Hoek, D., Yaya, F., Roelfsema, J., Pinelli, E., Van Knapen, F. and Kortbeek, L., 2009. Zoonotic parasites in fecal samples and fur from dogs and cats in the Netherlands. Vet. Parasitol., 163(1-2), 115-122.

Palmer, C.S., Robertson, I.D., Traub, R.J., Rees, R. and Thompson, R.C., 2010. Intestinal parasites of dogs and cats in Australia: the veterinarian's perspective and pet owner awareness. Vet. J., 183, 358-361.

Smith, A. and Whitfield, Y., 2012. House hold pets and zoonoses, In Canada, national collaborating center for environmental health. Ontario Veterinary College, University of Guelph, Canada.

Song, S., Lauber, C., Costello, E., Lozupone, C., Humphery, G., Berg-Lyons, D., Caporaso, J., et al., 2013. Cohabiting family members share microbiota with one another and with their dogs. E. Life., 10, 75-54.

Strohmeyer, R., Morley, P., Hyatt, D., Dargatz, D., Scorza, A. and Lappin, M., 2006. Evaluation of bacterial and protozoal contamination of commercially available raw meat diets for dogs. J. Am. Vet. Med. Assoc., 228, 537-542.

Stull, J. W., 2012. Pets as a source of zoonotic disease: An investigation into knowledge, attitudes and practices related to pet contact and associated zoonoses in low and high disease-risk households. PHD thesis presented to The University of Guelph, Canada, Pp 3.

Stull, J., Peregrine, A., Sargeant, J. and Weese, J., 2013. Pet husbandry and infection control practices related to zoonotic disease risks in Ontario, Canada. BMC Pub. Health., 13, 520 
Weese, J., Rousseau, J. and Arroyo, L., 2005. Bacteriological evaluation of commercial canine and feline raw diets. Can. Vet. J., 46, 513-516.

Westgarth, C., Pinchbeck, G., Bradshaw, J., Dawson, S., Gaskell, R. and Christley, R., 2008. Dog-human and dog-dog interactions of $260 \mathrm{dog}$ owning households in a community in Cheshire. Vet. Rec., 162(14), 436-42.

Yimer, E., Mesfin, A., Beyene, M., Bekele, A., Taye, G., Zewdie, B. and Alemayehu, T., 2012. Study on knowledge, attitude and dog ownership patterns related to rabies prevention and control in Addis Ababa, Ethiopia. Ethiop. Vet. J., 16(2), 27-39.

Zewdu, E., Semahegn, Y. and Mekibib, B., 2010. Prevalence of helminth parasites of dogs and owners awareness about zoonotic parasites in Ambo town, central Ethiopia. Ethiop. Vet. J., 14, 2. 